\title{
Historical load effects on fatigue of metallic railway bridges
}

Boulent Imam BSC, MSc, PhD

Senior Lecturer, Department of Civil and Environmental Engineering, University of Surrey, Guildford, UK (corresponding author:

b.imam@surrey.ac.uk)
Paul A. Salter BEng, MSc

Engineer, Ramboll UK Ltd, Southampton, UK

This paper presents load models for quantifying the effect of historical rail traffic on the remaining fatigue life of riveted bridges in the UK. In this study, three types of load models, based on realistic trains, accounting for differences in rail traffic composition, were developed and subsequently used to investigate their effect on the accumulation of fatigue damage in typical old metallic bridge structures. The overall findings showed that the increase in train axle loads from 1900 to 2010 is the main attributor to the significant increase in fatigue damage caused from modern trains compared with the residual fatigue damage from historical trains. These findings are particularly relevant to the majority of existing metallic rail bridges on the rail network, which have a span length of less than $10 \mathrm{~m}$. The findings show the importance of considering the effects of historical loading for more reliable fatigue assessment purposes, leading towards more efficient planning of bridge maintenance and renewal programmes.

\section{Introduction}

A vast number of existing metallic bridges in the British railway network, as well as many parts of Europe and North America, are either wrought-iron or early mild-steel riveted bridges. According to European railway bridge demographics (Bell, 2007), out of the 47000 metallic railway bridges in Europe, approximately 12000 are made of wrought-iron. About 30\% of the metallic bridges are over 100 years old. These bridges can be considered as fatigue-sensitive structures as they significantly precede any design methodology inclusive of fatigue-damaging effects. Although fatigue has been studied for over 100 years, the explicit inclusion of fatigue effects in the performance of bridges has only occurred since the 1970s in the UK (BS 5400 (BSI, 1980)). Over the last few decades, significant amounts of research have been carried out in attempts to understand and quantify the fatigue behaviour of riveted bridges (Akesson, 1994; Al-Emrani, 2005; Al-Emrani and Kliger, 2003; Imam, 2006; Imam et al., 2008, 2012; Righiniotis et al., 2008). These investigations have provided valuable insight by identifying, both experimentally as well as numerically, the factors that affect fatigue performance and the modes of initiation and propagation of fatigue damage in these types of bridges.

A fundamental part of keeping the existing railway network operating without having to replace existing structures unless absolutely necessary is to be able to accurately calculate their performance. In the case of metallic bridge structures, fatigue is one of the critical elements in the performance of the structure, especially as the only live loading experienced by these bridges is train loading which, by its inherent nature, is one of the most fatigue-damage inducing types of loading process. However, unlike other fatigue-inducing live loading, for example wind loading or highway loading, rail loading can be accurately predicted and modelled as it is a controlled process. The axle loads are known for all train types on the network and an estimation of the frequency of trains over a particular structure is possible; therefore, a reasonably accurate method can be used to gauge the fatigue damage in the bridge member being considered.

One of the key steps during fatigue analysis of bridge structures is the prediction of load effects; it is well known that fatigue damage is highly sensitive to stress range estimates. Accurate estimation of the remaining fatigue life of old metallic bridges, considering a safe-life approach, is highly dependent on accurate prediction of past, current and future damage accumulations. This is, in turn, reliant on accurate estimation of the load effects caused by railway traffic in each of these periods. The codes of practice for fatigue design and assessment often provide good information regarding modern (current-day) train loading and traffic. However, they lack information and guidance about historical (past) rail traffic, which is essential for quantifying the fraction of fatigue damage that has already accumulated in existing bridges. Literature considering the variations between historical (1900s) and modern train loading trends and the effects these have on old metallic bridge structures is limited.

This paper concentrates on the fatigue effects due to variations in train loading on riveted plate girder bridges with the aim of understanding the differing effects of historical and modern train loadings. The aim of the study was to identify where the majority of fatigue damage originates in old metallic bridges to allow a greater accuracy of fatigue analysis and therefore 
enable more accurate prediction of their remaining fatigue life. To this end, examples of historical train load models are reviewed first and a novel load model that captures variations in rail traffic composition from passenger-dominated to freight-dominated is developed. The load model, which is based on realistic trains, is then used on a number of typical case-study bridge structural models to investigate the effects of historical loading on the fatigue damage of old metallic bridges and to identify other parameters that affect fatigue behaviour.

\section{Historical rail traffic load models}

\subsection{Models available in the literature}

For historical railway bridges that were not designed for fatigue, to assume that they have been subjected to modern train loading since their initial construction, circa 1900, is an extremely conservative method to use, considering how sensitive fatigue damage is to small variations in load trends. On the other hand, completely neglecting the effects of historical rail traffic on their fatigue behaviour is likely to overestimate their remaining fatigue life. There is thus a genuine requirement to provide a standardised historical train load model for the purposes of more reliable fatigue assessment.

A detailed history of locomotive development and the significant changes to freight wagons and passenger coaches over time is given by Hayward $(2010,2013)$. The 1960s saw the introduction of fuel tanker bogie wagons weighing $100 \mathrm{t}$ loaded. These were followed by $100 \mathrm{t}$ mineral tipper wagons and coal hopper bogie wagons. Presently, modern freight trains typically induce $25 \mathrm{t}$ repetitive axle loads which have considerably increased outside the bounds of the historical design envelope, potentially having serious implications on the fatigue performance of existing bridges in the rail network.

A practical way of considering the cumulative effect of historical loading on bridge structures has been suggested by Akesson (1994). According to this method, the amount of damage that historical trains have caused to date can be estimated by transforming the freight tonnage amount per year into a number of equivalent freight train passages over the bridge. This approach provides a simplified, conservative way of quantifying fatigue damage based on a known statistical tonnage per year, without taking into account the variation in train layouts or axle spacings that have occurred during the lifetime of the bridge. However, in many cases, axle weights and spacings, rather than train frequencies, can be the governing factors that control the remaining fatigue life of bridges.

A past traffic load model has been suggested by the International Union of Railways (UIC, 1986). The model is divided into six different time periods and each period is represented by a number of representative trains for passenger and freight traffic, including their daily frequency. This load model has been used for the fatigue assessment of a real casestudy metallic railway bridge in Italy, where it was shown that the fatigue damage produced by historical trains is not insignificant (Pipinato et al., 2012).

One of the few load models that have been developed to capture historical rail traffic and its effect on the fatigue damage of old metallic bridges is that proposed by Imam and Righiniotis (2010). The basis of this model, which was developed in collaboration with Network Rail based on realistic train configurations, was derived from BS 5400: Part 10 (BSI, 1980) which includes modern train load models. BS 5400 defines three variations of fatigue loading - light, medium and heavy - which respectively correlate to passenger-only lines, mixed passenger and freight lines and dedicated freight lines, and provides details about the types and frequencies of trains to be used in each model, as shown in Table 1. The load model developed by Imam and Righiniotis (2010), shown in Table 2, is divided into three distinct periods between 1900 and 1970 and only considers the medium-traffic variation. This model was developed from the number of trains per year of the medium-traffic variation suggested in BS 5400 (Table 1). Accordingly, historical passenger trains in the historical load model were determined by equating the total historical passenger train and the local suburban service train to the modern passenger diesel train (no. 5). The historical freight train assumed for the historical load model equates to the sum of the BS 5400 modern heavy freight trains (no. 7 and no. 8) and the steel train per year (no. 1). Therefore, the total number of passenger trains per year is 22500 with the addition of 10500 freight trains per year. As opposed to the model developed by Akesson (1994), this historical load model not only takes into

Table 1. Rail traffic types suggested in BS 5400 (BSI, 1980)

\begin{tabular}{|c|c|c|c|c|}
\hline $\begin{array}{l}\text { Traffic } \\
\text { type }\end{array}$ & $\begin{array}{l}\text { Train } \\
\text { type }\end{array}$ & $\begin{array}{c}\text { Train } \\
\text { weight: } t\end{array}$ & $\begin{array}{l}\text { Annual train } \\
\text { frequency }\end{array}$ & $\begin{array}{l}\text { Total annual } \\
\text { tonnage: Mt }\end{array}$ \\
\hline \multirow[t]{4}{*}{ Heavy } & No. 7 & 1120 & 4821 & $5 \cdot 40$ \\
\hline & No. 8 & 1120 & 7232 & $8 \cdot 10$ \\
\hline & No. 9 & 852 & 15845 & $13 \cdot 50$ \\
\hline & & & Total & $27 \cdot 00$ \\
\hline \multirow[t]{5}{*}{ Medium } & No. 5 & 600 & 22500 & $13 \cdot 50$ \\
\hline & No. 7 & 1120 & 2411 & $2 \cdot 70$ \\
\hline & No. 8 & 1120 & 6027 & $6 \cdot 75$ \\
\hline & No. 1 & 1794 & 2257 & 4.05 \\
\hline & & & Total & $27 \cdot 00$ \\
\hline \multirow[t]{7}{*}{ Light } & No. 1 & 1794 & 752 & $1 \cdot 35$ \\
\hline & No. 2 & 372 & 14516 & $5 \cdot 40$ \\
\hline & No. 3 & 344 & 23546 & $8 \cdot 10$ \\
\hline & No. 4 & 172 & 47093 & $8 \cdot 10$ \\
\hline & No. 5 & 600 & 4500 & $2 \cdot 70$ \\
\hline & No. 6 & 572 & 2360 & $1 \cdot 35$ \\
\hline & & & Total & $27 \cdot 00$ \\
\hline
\end{tabular}


Table 2. Medium-traffic historical (1900-1970) and modern (1970) train load model ( $F=$ freight, $P=$ passenger, $L S=$ local suburban)

\begin{tabular}{|c|c|c|c|c|c|c|}
\hline Period & $\begin{array}{l}\text { Traffic } \\
\text { type }\end{array}$ & Locomotive type & $\begin{array}{l}\text { Wagon axle } \\
\text { weight: } t\end{array}$ & $\begin{array}{l}\text { Number of } \\
\text { wagons }\end{array}$ & $\begin{array}{l}\text { Train } \\
\text { speed }\end{array}$ & $\begin{array}{l}\text { Annual } \\
\text { frequency }\end{array}$ \\
\hline \multirow[t]{3}{*}{ 1900-1920 } & $\mathrm{F}$ & 0-6-0 Superheated freight engine & $2 \times 8$ & 30 & $30 \mathrm{~m} / \mathrm{h}$ & 10500 \\
\hline & $P$ & 4-4-0 Passenger engine & $4 \times 8$ & 8 & $50 \mathrm{~m} / \mathrm{h}$ & 11250 \\
\hline & LS & 0-4-4 Tank engine & $4 \times 8$ & 4 & $30 \mathrm{~m} / \mathrm{h}$ & 11250 \\
\hline \multirow[t]{3}{*}{ 1920-1940 } & $\mathrm{F}$ & 0-6-0 Superheated freight engine & $2 \times 10$ & 40 & $40 \mathrm{~m} / \mathrm{h}$ & 10500 \\
\hline & $P$ & $\begin{array}{l}\text { 4-6-0 Superheated mixed traffic } \\
\text { engine }\end{array}$ & $4 \times 9$ & 12 & $60 \mathrm{~m} / \mathrm{h}$ & 18000 \\
\hline & LS & 0-4-4 Tank engine & $4 \times 8$ & 4 & $30 \mathrm{~m} / \mathrm{h}$ & 4500 \\
\hline \multirow[t]{3}{*}{ 1940-1970 } & $\mathrm{F}$ & 2-8-0 Freight engine & $2 \times 10$ & 40 & $40 \mathrm{~m} / \mathrm{h}$ & 10500 \\
\hline & $P$ & $\begin{array}{l}\text { 4-6-0 Superheated mixed traffic } \\
\text { engine }\end{array}$ & $4 \times 9$ & 15 & $70 \mathrm{~m} / \mathrm{h}$ & 18000 \\
\hline & LS & 0-4-4 Tank engine & $4 \times 8$ & 6 & $40 \mathrm{~m} / \mathrm{h}$ & 4500 \\
\hline \multirow{4}{*}{1970 onwards } & $\mathrm{F}$ & Steel train (BS 5400 no. 1) & $6 \times 18.5$ & 15 & $80 \mathrm{~km} / \mathrm{h}$ & 2257 \\
\hline & $P$ & $\begin{array}{l}\text { Diesel hauled passenger train } \\
\text { (BS } 5400 \text { no. 5) }\end{array}$ & $4 \times 10$ & 12 & $160 \mathrm{~km} / \mathrm{h}$ & 22500 \\
\hline & $\mathrm{F}$ & Heavy freight train (BS 5400 no. 7) & $4 \times 25$ & 10 & 72 km/h & 2411 \\
\hline & $\mathrm{F}$ & Heavy Train (BS 5400 no. 8) & $2 \times 25$ & 20 & 72 km/h & 6027 \\
\hline
\end{tabular}

account changes in train frequencies over time but it also captures changes in axle loads as well as axle spacings.

In this paper, the model is further extended, allowing it to be used for passenger-only and freight-dedicated lines corresponding to light and heavy fatigue loading conditions according to BS 5400. For example, a bridge located on a freight route that is used to transport heavy freight such as iron ore or coal is likely to experience the heavy traffic type while a bridge located in the vicinity of a city centre is more likely to experience passenger traffic only.

\subsection{Light and heavy historical train models}

There is a distinct difference between the haulage capacity of modern and historical freight trains. For example, the freight train defined in Table 2 for the period 1900-1920 has a capacity of $570 \mathrm{t}$ whereas the modern heavy freight train (no. 7) has a capacity of $1120 \mathrm{t}$. Due to this difference in tonnage, the formation of the heavy-traffic historical model was based on tonnage per train rather than the frequency of trains per year. The modern total tonnage was divided by the haulage capacity of the historical freight train to calculate the frequency of historical freight trains required to haul the tonnage annually. The tonnage hauled per year for each historical period was proportionally adjusted against the modern tonnage provided in Table 1 using historical freight data (Coucher et al., 2008; IMechE, 2009; Leach, 2002; Whiteing, 2003). As shown in Figure 1, historical freight data are available for the period between 1950 and 2010; for the pre-1950 period, the data were estimated as the sources (Coucher et al., 2008; IMechE, 2009; Leach, 2002; Whiteing, 2003) did not contain any historical data. The heavy-traffic historical model is presented in Table 3 .

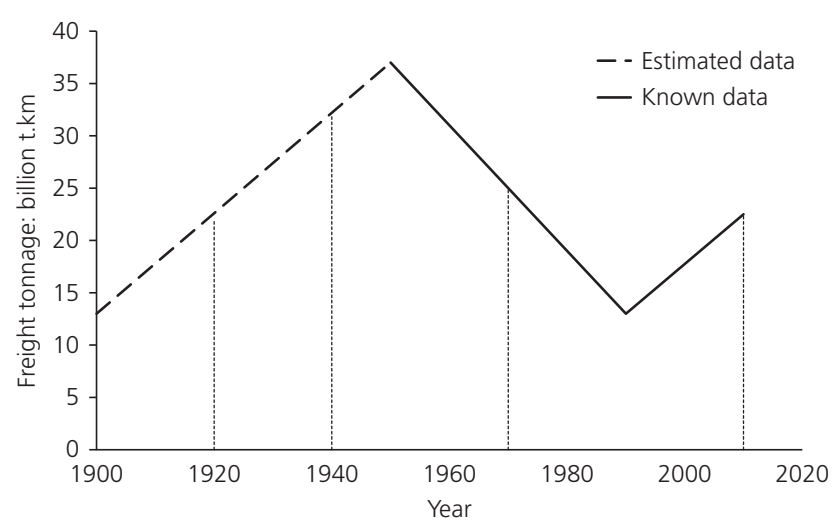

Figure 1. Historical freight tonnage data (Coucher et al., 2008; IMechE, 2009; Leach, 2002; Whiteing, 2003)

The light-traffic historical model, unlike the heavy-traffic model, was not created from the annual tonnage of trains as the weight of passenger coaches have not changed significantly through the periods (Hayward, 2010, 2013). The light-traffic model was created by considering the amount of coaches required per year to move the volume of passengers. This was proportionally adjusted from known historical passenger volume data (Coucher et al., 2008) against Table 1 (BSI, 1980) to back-calculate the annual train frequency required for each period. The historical passenger volume data used to create the adjusted weighting for each historical period were obtained from Coucher et al. (2008). The light-traffic model is presented in Table 4. The layout of all the historical trains shown in Tables 3 and 4 are shown in Figure 2 (Imam, 2006; Imam et al., 2006), while the layouts of the modern trains for the period 1970 can be found in BS 5400 (BSI, 1980). 
Table 3. Heavy-traffic historical and modern train load model

\begin{tabular}{|c|c|c|c|c|c|c|}
\hline Period & $\begin{array}{l}\text { Traffic } \\
\text { type }\end{array}$ & Locomotive type & $\begin{array}{l}\text { Wagon axle } \\
\text { weight: } t\end{array}$ & $\begin{array}{l}\text { Number of } \\
\text { wagons }\end{array}$ & Train speed & $\begin{array}{c}\text { Annual } \\
\text { frequency }\end{array}$ \\
\hline 1900-1920 & $\mathrm{F}$ & 0-6-0 Superheated freight engine & $2 \times 8$ & 30 & $30 \mathrm{~m} / \mathrm{h}$ & 48421 \\
\hline 1920-1940 & $\mathrm{F}$ & 0-6-0 Superheated freight engine & $2 \times 10$ & 40 & $40 \mathrm{~m} / \mathrm{h}$ & 45505 \\
\hline 1940-1970 & $\mathrm{F}$ & 2-8-0 Freight engine & $2 \times 10$ & 40 & $40 \mathrm{~m} / \mathrm{h}$ & 48825 \\
\hline \multirow[t]{3}{*}{1970 onwards } & $\mathrm{F}$ & Mixed freight (BS 5400 no. 9) & $2 \times 7,4 \times 20,6 \times 20$ & 12 & $120 \mathrm{~km} / \mathrm{h}$ & 4821 \\
\hline & $\mathrm{F}$ & Heavy freight train (BS 5400 no. 7) & $4 \times 25$ & 10 & $120 \mathrm{~km} / \mathrm{h}$ & 7232 \\
\hline & $\mathrm{F}$ & Heavy freight train (BS 5400 no. 8) & $2 \times 25$ & 20 & $120 \mathrm{~km} / \mathrm{h}$ & 15845 \\
\hline
\end{tabular}

Table 4. Light-traffic historical and modern train load model

\begin{tabular}{lllrrrr} 
Period & $\begin{array}{l}\text { Traffic } \\
\text { type }\end{array}$ & Locomotive type & $\begin{array}{c}\text { Wagon axle } \\
\text { weight: t }\end{array}$ & $\begin{array}{c}\text { Number of } \\
\text { wagons }\end{array}$ & $\begin{array}{c}\text { Train } \\
\text { speed }\end{array}$ & $\begin{array}{c}\text { Annual } \\
\text { frequency }\end{array}$ \\
\hline $1900-1920$ & $P$ & 4-4-0 Passenger engine & $4 \times 8$ & 30 & $50 \mathrm{~m} / \mathrm{h}$ & 41163 \\
& LS & 0-4-4 Tank engine & $4 \times 8$ & 8 & $30 \mathrm{~m} / \mathrm{h}$ & 82326 \\
$1920-1940$ & P & 4-6-0 Superheated mixed traffic engine & $4 \times 9$ & 12 & $60 \mathrm{~m} / \mathrm{h}$ & 58888 \\
& LS & 0-4-4 Tank engine & $4 \times 8$ & 4 & $30 \mathrm{~m} / \mathrm{h}$ & 44165 \\
$1940-1970$ & P & 4-6-0 Superheated mixed traffic engine & $4 \times 9$ & 15 & $70 \mathrm{~m} / \mathrm{h}$ & 44217 \\
& LS & 0-4-4 Tank engine & $4 \times 8$ & 6 & $40 \mathrm{~m} / \mathrm{h}$ & 41454 \\
1970 onwards & F & Steel train (BS 5400 no. 1) & $6 \times 18.5$ & 15 & $80 \mathrm{~km} / \mathrm{h}$ & 752 \\
& P & Electric multiple unit (BS 5400 no. 2) & $4 \times 10$ & 8 & $145 \mathrm{~km} / \mathrm{h}$ & 14516 \\
& LS & Southern region suburban (BS 5400 no. 3) & $9.5,11,13$ & 12 & $145 \mathrm{~km} / \mathrm{h}$ & 23546 \\
& LS & Southern region suburban (BS 5400 no. 4) & $9.5,11,13$ & 6 & $145 \mathrm{~km} / \mathrm{h}$ & 47093 \\
& P & Diesel hauled passenger train (no. 5) & $4 \times 10$ & 12 & $160 \mathrm{~km} / \mathrm{h}$ & 4500 \\
& P & Electric hauled passenger train (no. 6) & $4 \times 10$ & 12 & $160 \mathrm{~km} / \mathrm{h}$ & 2360 \\
& & & & &
\end{tabular}

All the developed load models were based on realistic train configurations.

\section{Fatigue assessment}

Historically, in the rail network, a few typical bridge designs were commonly used. In general, these can be categorised by the span length of the bridge. Short-span bridges are mainly masonry arches or plate girder bridges. For medium-span bridges, truss girders or plate girder arches were preferred, with plate girder arches and large box section bridges being preferred for longer spans (Hayward, 2010, 2013). The majority of the bridges on the rail network have a span around or less than $10 \mathrm{~m}$ (Hayward, 2010, 2013; Imam, 2006) and are of plate girder construction. For example, about $45 \%$ of the metallic bridges in Europe have a span of less than $10 \mathrm{~m}$ (Bell, 2007). Of the metallic bridge types used, truss girder bridges and box section bridges are less fatigue-sensitive in terms of their main truss members due to their long span lengths; the dead load dominates a high percentage of the available capacity and therefore reduces the fluctuating live-load stress range on those elements. On the other hand, plate girder bridges and the stringers and cross-girders of truss bridges work in bending and therefore these sections see high fluctuating tensile stresses as the live load dominates the available capacity due to the shorter span length. As a consequence, short-span plate girder bridges can be considered as the most fatigue-sensitive bridge type on the railway network.

For the purposes of comparing the effect of varying historical loading on fatigue, single-span riveted plate girder bridges are considered in this paper. The bridges comprise two girders with equal load share supporting a single track via a simple ballasted troughing deck. For analysis of the main girders, a standard bridge set consisting of 17 bridges was created to represent riveted plate girder bridges with spans ranging from $4 \mathrm{~m}$ to $20 \mathrm{~m}$ in $1 \mathrm{~m}$ increments. These bridges were based on a standard cross-section layout - a simply supported bridge with a trough deck supporting ballast and single track, connected to two plate girders, as shown in Figure 3.

The parameters investigated in terms of their influence on the fatigue behaviour of the bridges are

- the axle spacing of the trains and the bridge span length

- the differences between modern and historical trains in the train load models

- the variance created between the three train load models (light-, medium- and heavy-traffic models) 


\begin{tabular}{|c|c|}
\hline Locomotive/wagon type & Axle spacings (in $\mathrm{m}$ ) and weights (in $\mathrm{t}$ ) \\
\hline 0-6-0 Superheater freight engine & 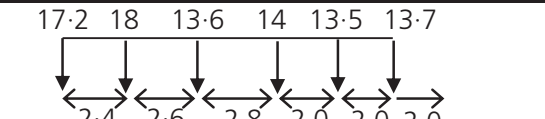 \\
\hline 4-4-0 Passenger engine & $19.1 \quad 17.8 \quad 17.2 \quad 14 \quad 13.513 .7$ \\
\hline 0-4-4 Tank engine & 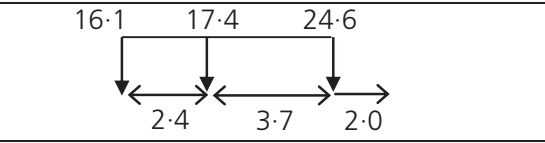 \\
\hline 4-6-0 Superheated mixed traffic engine & $\underbrace{17.9}_{2.7} 18.118 .2 \quad 18 \quad \frac{18.2}{217.5} 17.9$ \\
\hline 2-8-0 Freight engine & $9215.515 .616 \quad 16$ 18.3 17.5 17.9 \\
\hline Freight wagon & 8 or $10 \quad 8$ or 10 \\
\hline Passenger/suburban wagon & 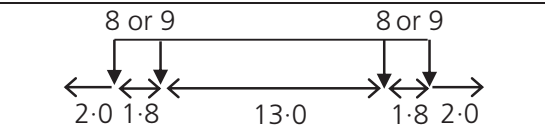 \\
\hline
\end{tabular}

Figure 2. Axle configurations of historical trains used in the load models

Main girders

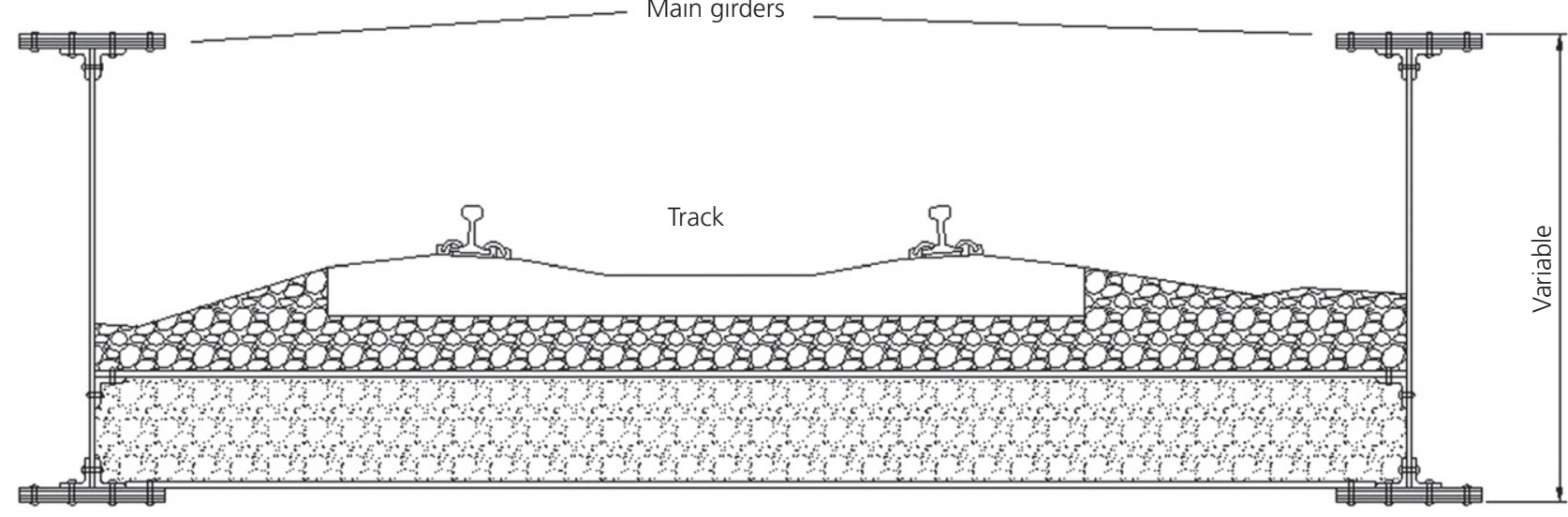

Troughing

Figure 3. Standard bridge set: cross-section at midspan

- the difference between wrought-iron and mild-steel riveted bridges

- the year of construction of the bridge.
To ensure the analyses are representative, each bridge was designed for a working stress limit of $77.5 \mathrm{MPa}$ for wrought iron and $100 \mathrm{MPa}$ for mild steel, which were typical values 
employed around the 1900s for design (Fitzmaurice, 1895). Live loading was based on the equivalent uniform distributed load curve design model defined by Hayward (2010, 2013). The bridges were designed so that the combination of live-load stress and total dead-load stress equalled the working stress limit (Fitzmaurice, 1895; Hayward, 2010, 2013). This method may provide higher utilisation in the main girders than existing bridges. However, the aim of the analyses was to find a correlation in the bridge results rather than explicitly quantifying the fatigue failure point of the bridges.

The design process was based on only varying the strength of the main girders between each bridge. As span length increases the bending moment due to the total dead and live load will also increase. To ensure that the combined maximum total dead-load and live-load stresses on the main girder at midspan equals the working stress limit for each span length, the strength of the girder must increase. Therefore, an iterative process was used to calculate girder strength. The combined live-load and total dead-load stress was equated to the working stress limit by iterating through standard riveted girder section sizes (Fitzmaurice, 1895). Figures 4 and 5 show the live-load and the total dead-load stresses and the strength of the girders, respectively.

The dynamic influence of the passage of trains over the bridge was also taken into account. The dynamic amplification factor (Daf) for each train depends on the span length and the natural frequency of the structure, with each bridge having varying Dafs depending on the velocity of the train. The Daf is given by (Network Rail, 2006)

1. $\mathrm{Daf}=1+0 \cdot 5\left(\phi_{1}+\frac{\phi_{11}}{2}\right)$

where $\phi_{1}$ is associated with the inertial response of the bridge and $\phi_{11}$ is associated with track irregularities. The train speeds used for calculation of the Dafs are shown in Tables 2-4.

The Dafs for each train and for each span were taken into account in the assessment procedure by multiplying the Dafs obtained from Network Rail (2006) with the static stresses obtained from the bridge analysis. An overview of the effect of the Daf on the fatigue damage of metallic bridges and the range of values expected in such bridges can be found elsewhere (Imam et al., 2006).

The standard bridge set was assessed for fatigue damage occurring in the bottom flange of the main girder due to rivet holes at midspan, as shown in the bridge detail in Figure 6. This detail is classified as class D according to BS 5400: Part 10 (BSI, 1980). Analysis of the bridge set was carried out by developing a structural model of each bridge using the

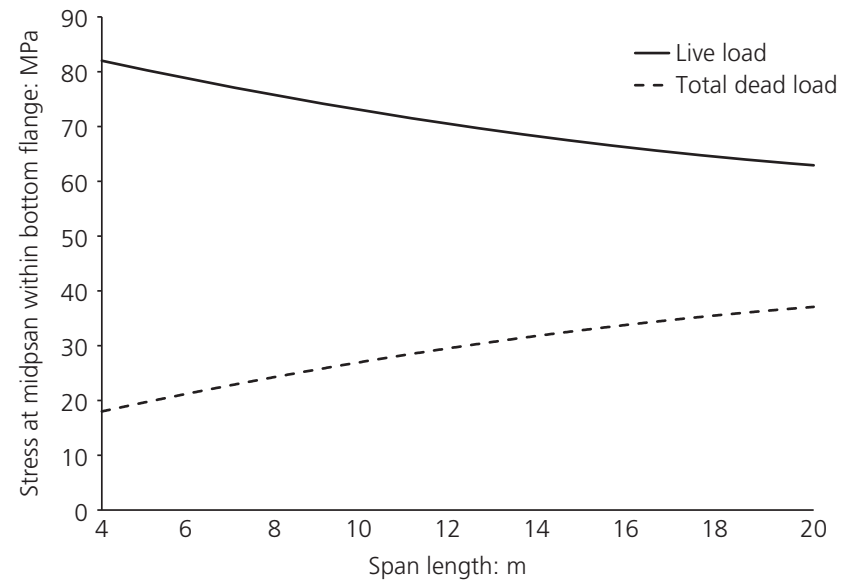

Figure 4. Standard bridge set: live-load and total dead-load stress for main girders

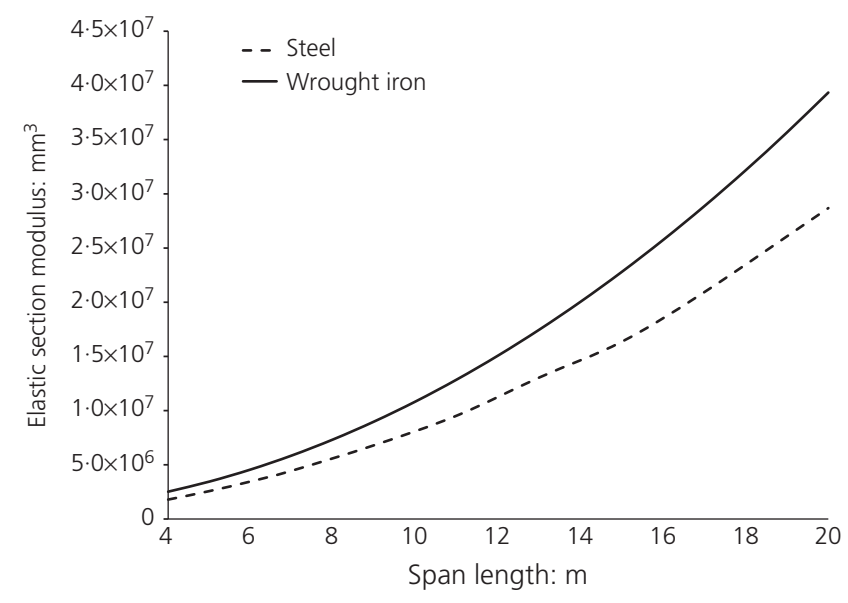

Figure 5. Standard bridge set: strength of mild-steel and wrought-iron main girders

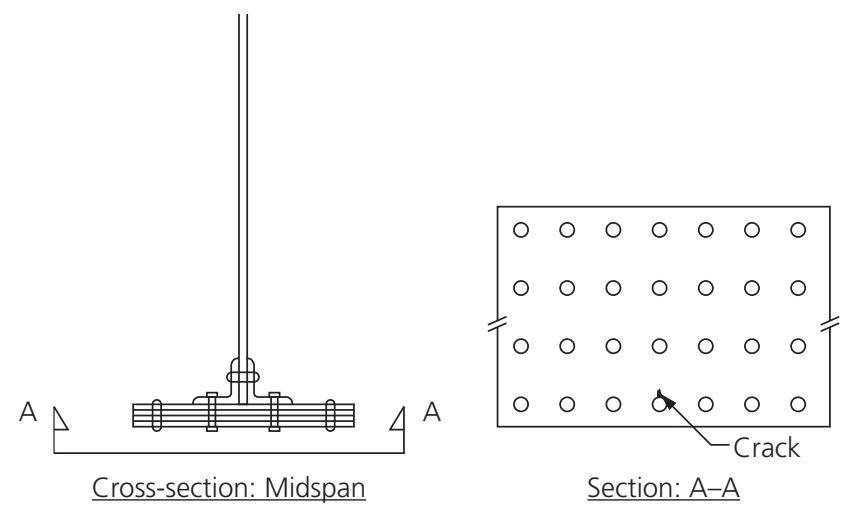

Figure 6. Fatigue detail of bottom flange of main girder 
finite-element program Strap 2010. The models comprised line (beam) elements to represent the bridge members with each element having a representative section and material property. Linear static analysis was carried out to extract the stress histories resulting from the passages of the trains over each bridge span. An influence table for the bending moment at midspan due to a unit load traversing the bridge representing one train axle was obtained from the analysis; these data were then combined through the superposition rule to produce train stress histories, which were then converted into stress range histograms through rainflow counting and used for the calculation of fatigue damage. The fatigue damage was estimated through Miner's rule (Miner, 1945), which forms the basis of a major part of fatigue assessment codes worldwide, including the UK fatigue assessment code for metallic railway bridges (Network Rail, 2006), which is used in this paper. The cumulative fatigue damage, $D$, can be expressed as

2. $D=\sum_{i=1}^{k} \frac{n_{i}}{N_{i}}$

where $n_{i}$ is the number of applied cycles at a stress range $\Delta \sigma_{i}$ and $N_{i}$ is the corresponding number of cycles to failure at the same stress range $\Delta \sigma_{i}$ obtained from the relevant

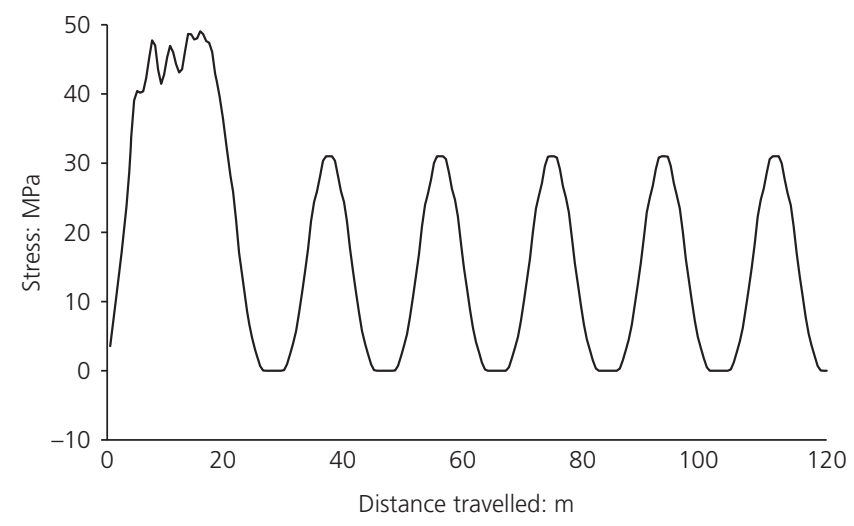

Figure 7. Stress history in main girder for a 1900-1920 passenger train (stress- number of cycles) $S-N$ curve of the bridge detail classification considered. According to Miner's rule, fatigue failure occurs when $D 1$.

For the purposes of the fatigue damage calculations, the fatigue limit was not considered and all stress ranges, even below the fatigue limit, were assumed to contribute to fatigue damage accumulation, which is a conservative assumption.

\section{Results and discussion}

\subsection{Effect of train axle spacing}

It can be expected that there is a fatigue damage relationship between the span length of the bridge and the axle spacing of the train. Key trends can be identified in the layout of the train axles and the critical effects these trends have on fatigue damage. Locomotive engines make up only a small percentage of the total axles of an entire train. The engine and tender axles are typically between $1.5 \mathrm{~m}$ and $3 \mathrm{~m}$ spacing and generally are the heaviest loaded axles. Due to this close axle spacing, the engine loading often acts as a uniformly distributed load rather than individual axles. For this reason, the engine locomotive produces only one stress cycle per train journey, which is predominantly the single largest stress range in the load spectrum for that train, as can be seen in Figure 7.

For both historical and modern trains in the train load models, a passenger train represents a key identifiable axle trend. The passenger coach considered is formed of four axles, with two axle pairs at either end of the coach. The axles within the pairs are spaced $1 \cdot 5-3 \mathrm{~m}$ apart and between $1 \mathrm{~m}$ and $3 \mathrm{~m}$ from the end couplers of the coach. The central spacing between the axle pairs is between $11.5 \mathrm{~m}$ and $13 \mathrm{~m}$. This creates four axles evenly spaced between $1.5 \mathrm{~m}$ and $3 \mathrm{~m}$ with a significant gap of 11.5-13 m before the next set of four closely spaced axles, as shown in Figure 8. Similarly to the engine and tender trends, the axles of the coaches are closely grouped together and do not cause large stress range amplitudes themselves. However, an increased spacing between the axle groups will cause large stress range amplitudes caused by the full loading and complete unloading of the bridge.

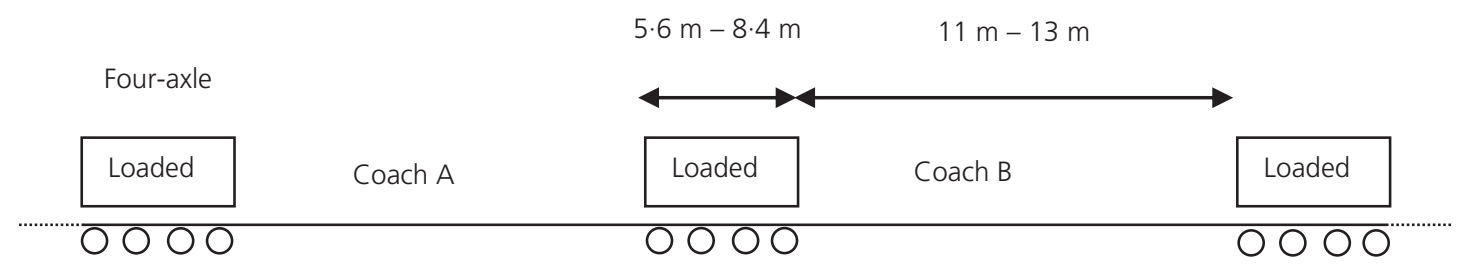

Figure 8. Coach axle trend 
Figure 7 shows the stress history obtained from the passage of the 1900-1920 passenger train over the $9 \mathrm{~m}$ span standard bridge and provides examples of the axle trends described above. The first stress cycle from $0 \mathrm{~m}$ to $30 \mathrm{~m}$ represents the engine and the front of the first coach travelling over the bridge. Each stress cycle of the evenly spaced equal-amplitude stress cycles from $30 \mathrm{~m}$ to $160 \mathrm{~m}$ represents the grouping of the four coach axles. The $4 \mathrm{~m}$ of zero stress between each coach cycle represents the difference between the central coach axle spacing and the span length which, in this case, is equal to $4 \mathrm{~m}(13-9 \mathrm{~m})$.

In addition to the passenger coach axle trend, the effects of a freight train no. 7 wagon can be added. This wagon represents the $100 \mathrm{t}$ coal and mineral wagon used since the 1970 s (Hayward, 2010, 2013). The axle spacings for these wagons fall within the bounds shown in Figure 8. The axle loads for these wagons are approximately double the axle loads of the passenger coaches, causing significantly greater fatigue damage than the equivalent coach.

The final key axle trend identified was for historical freight wagons and modern freight train no. 8 wagons, which have a short wagon length. The historical freight wagons consist of two axles spaced at $3 \mathrm{~m}$ with $2 \mathrm{~m}$ spacing between adjoining wagon axles. For the modern freight train no. 8 wagons, this extends to $5.5 \mathrm{~m}$ spacing between wagon axles and $3.5 \mathrm{~m}$ between adjoining wagon axles. The historical freight wagons produced the smallest amplitude stress fluctuations of all the trains and, for most bridges, can be treated as a uniformly distributed load for fatigue assessments. For longer span bridges (over $17 \mathrm{~m}$ ), the modern freight wagon can also be considered as a uniformly distributed load for fatigue assessments. However, for spans under $10 \mathrm{~m}$, the axle spacing to span length ratio becomes critical to the scale of the fatigue damage caused by freight train no. 8 wagons. Figure 9 shows the stress histories for a freight train no. 8 wagon on three varying spans of less than $10 \mathrm{~m}$. The variance in the amplitudes of the stress cycles between span lengths is critical to the change in fatigue damage between spans.

\subsection{Comparison of modern and historical trains}

A comparison of the fatigue damage due to historical and modern train types was carried out using the standard bridge set. Figure 10 shows the total fatigue damage due to historical trains against the modern trains in the medium-traffic model. The historical trains considered are representative of the period 1900-1970 and account for all the fatigue damage in this period; the modern trains represent fatigue damage from 1970 onwards until the present. The results in Figure 10 and subsequent figures relating to fatigue damage were normalised by the highest peak point in order to identify the trends and

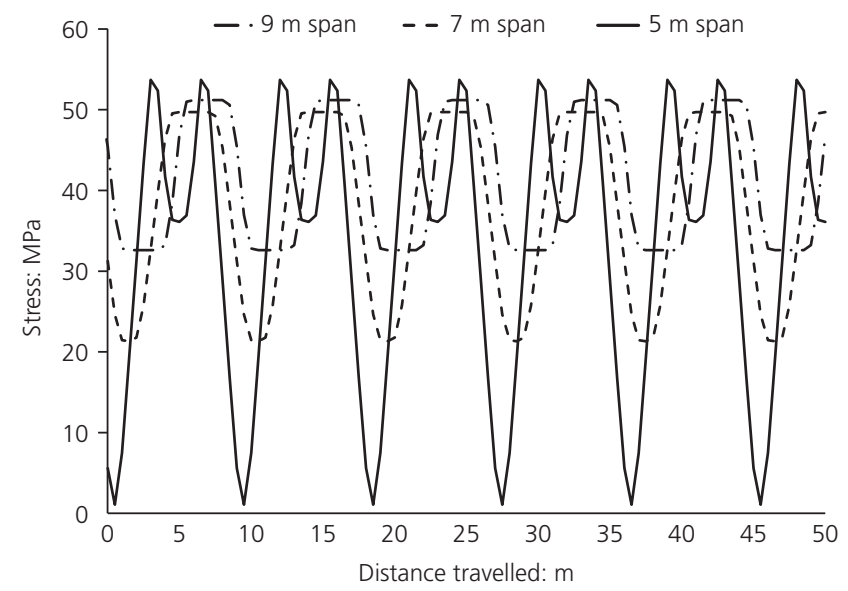

Figure 9. Stress histories of freight train no. 8 wagons over different spans

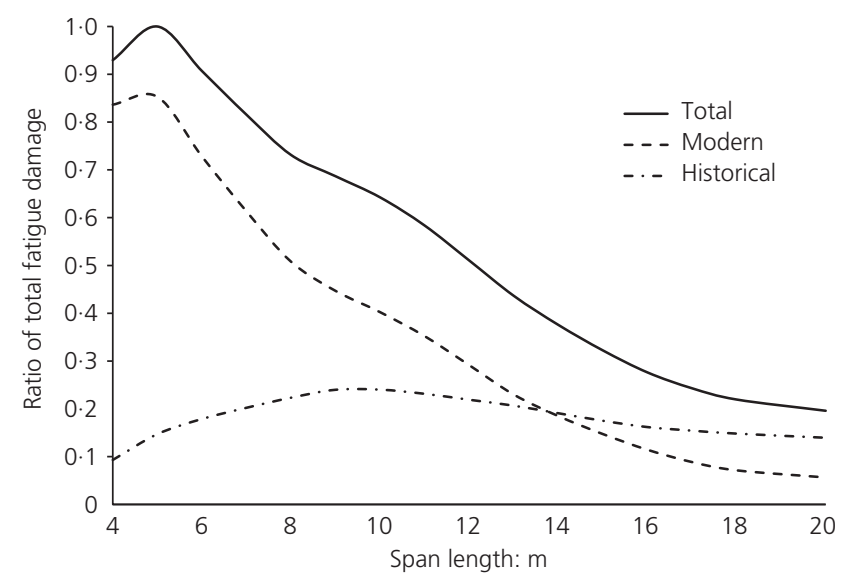

Figure 10. Fatigue damage produced by modern and historical loading

relative differences between the different types of loading rather than providing an explicit estimate of fatigue damage.

These result in Figure 10 show that, for bridges around 100 years old that have been subjected to medium-traffic conditions, modern trains cause the majority of fatigue damage for bridge spans of 4-14 m. In particular, fatigue damage in bridge spans under $9 \mathrm{~m}$ can be seen to be heavily dominated by modern trains, which demonstrates the criticality of shortspan bridges being particularly sensitive to fatigue from modern train loads (Hayward, 2010, 2013). For bridge spans over $14 \mathrm{~m}$, historical trains produced the highest proportion of the fatigue damage. For example, for a $9 \mathrm{~m}$ bridge, approximately $70 \%$ of the fatigue damage can be attributed to modern 
loading and the remaining $30 \%$ to historical trains. On the other hand, for a $16 \mathrm{~m}$ bridge, approximately $60 \%$ of the damage is attributed to historical trains whereas the remaining $40 \%$ is due to modern rail traffic. The variables that create this distinct difference in fatigue damage due to modern and historical trains are

the length of service for each train type

- the physical length of the trains (i.e. the number of wagons/coaches)

- the engine locomotive axle loads

- the wagon and coach axle loads

- the annual frequency of the train types

- the train speeds (which affect the applied Daf)

- the type of axle grouping trains in each period (short axle spacing or long axle spacing).

To understand which trains cause the most fatigue damage for particular span lengths, the critical variables were removed to create a standardised train set for comparison. The standardised variables across this train set were as follows.

- The train length was assumed to consist of the engine and five trailing units only.

- A period of 1 year for all trains was used for the comparison.

- 10000 trains per year for each train type was assumed.

- The remaining variables were left independent for each train type.
As can be seen in Figure 11, the standardised train results show that, for span lengths less than $10 \mathrm{~m}$, modern trains (BS 5400 nos 1 to 8) cause significantly greater fatigue damage than their historical counterparts. For span lengths of 10-18 m, modern trains, excluding the BS 5400 no. 7 freight train, cause similar fatigue damage as the historical trains, with both types showing a slow linear change across these span lengths. BS 5400 nos 7 and 8 freight trains have the greatest axle load ( $25 \mathrm{t} / \mathrm{axle})$ of all the trailing unit types (BSI, 1980). All other units range between 8 and 13 t/axle. The damaging effect of these high axle loads can be seen in the results plotted in Figure 11. The increased axle loads of modern freight trains create similarly increased stress ranges in bridge spans of the same magnitude. However, the relationship between stress range and fatigue damage is cubed or higher, therefore any increase in stress range is vastly magnified for the corresponding fatigue damage, as shown in Figures 12 and 13, where the contribution of each train type to total fatigue damage is shown for bridges of $5 \mathrm{~m}$ and $10 \mathrm{~m}$ span, respectively.

\subsection{Light, medium and heavy historical load models}

The light- and heavy-traffic models presented in Tables 3 and 4 were developed based on the modern load models of BS 5400: Part 10 (BSI, 1980), which represent bridges that solely see either passenger trains or freight trains, respectively. A bridge subjected to the light-traffic model could be representative of a bridge located just outside one of the main London terminus

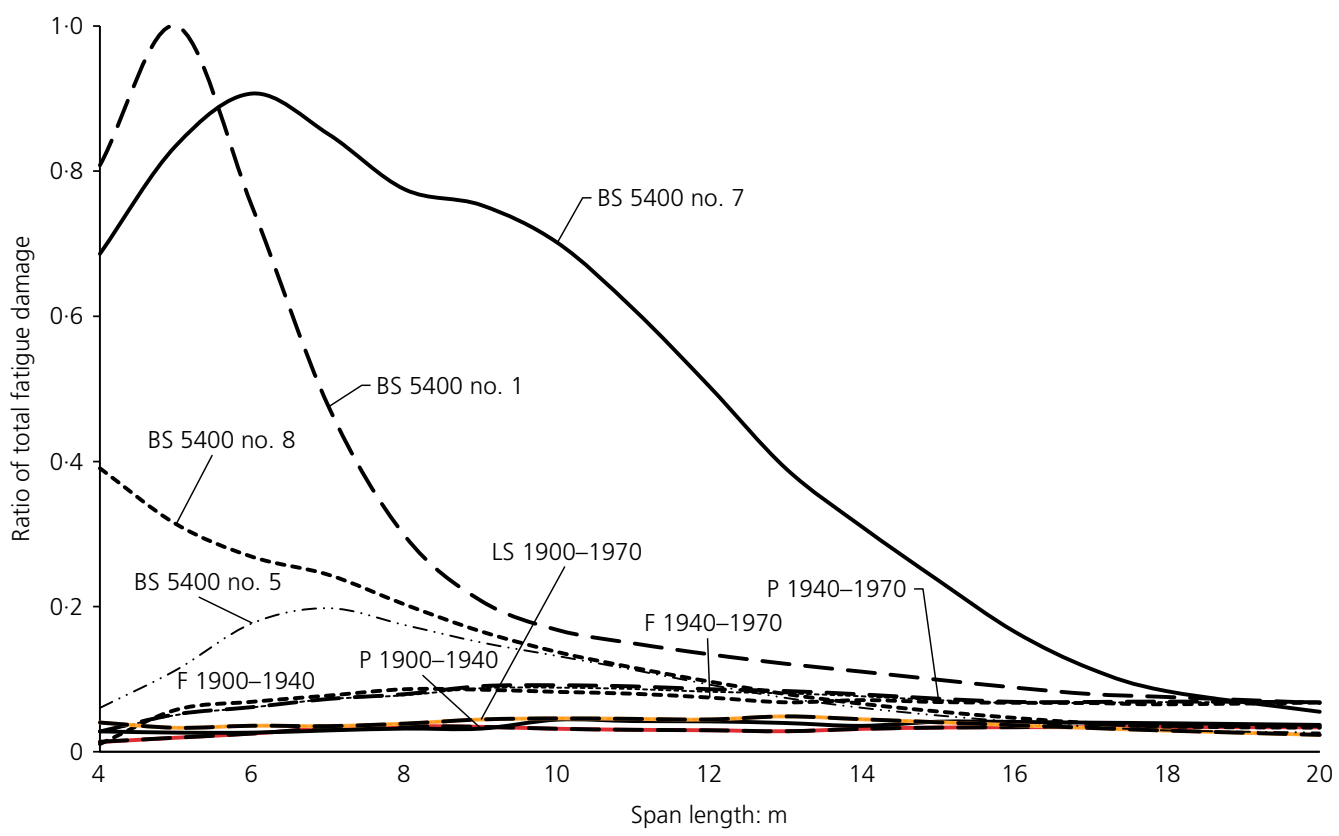

Figure 11. Individual train fatigue damage for the standardised train set $(F=$ freight, $P=$ passenger, $L S=$ local suburban) 


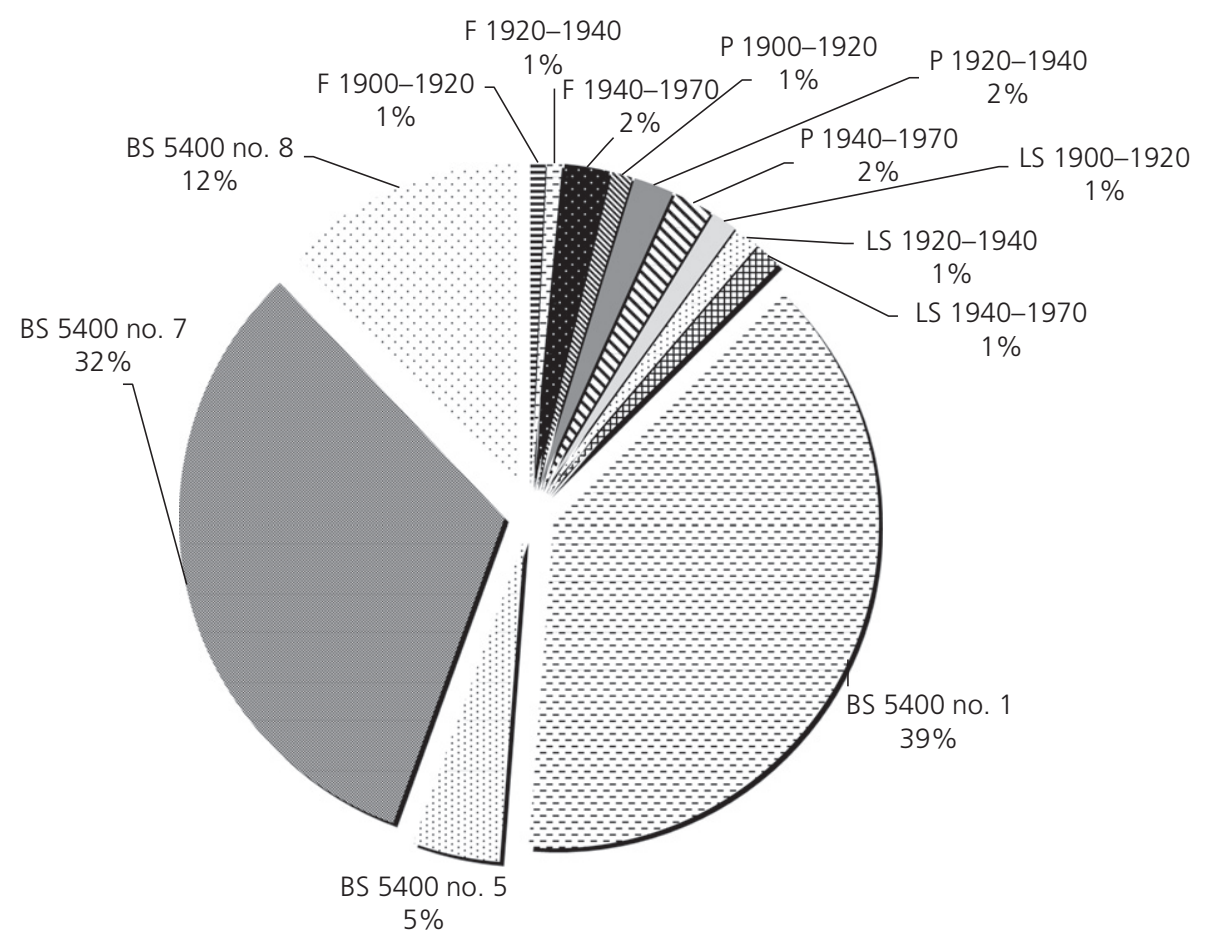

Figure 12. Standardised train set: fatigue damage for a $5 \mathrm{~m}$ bridge span ( $F=$ freight, $P=$ passenger, $L S=$ local suburban)

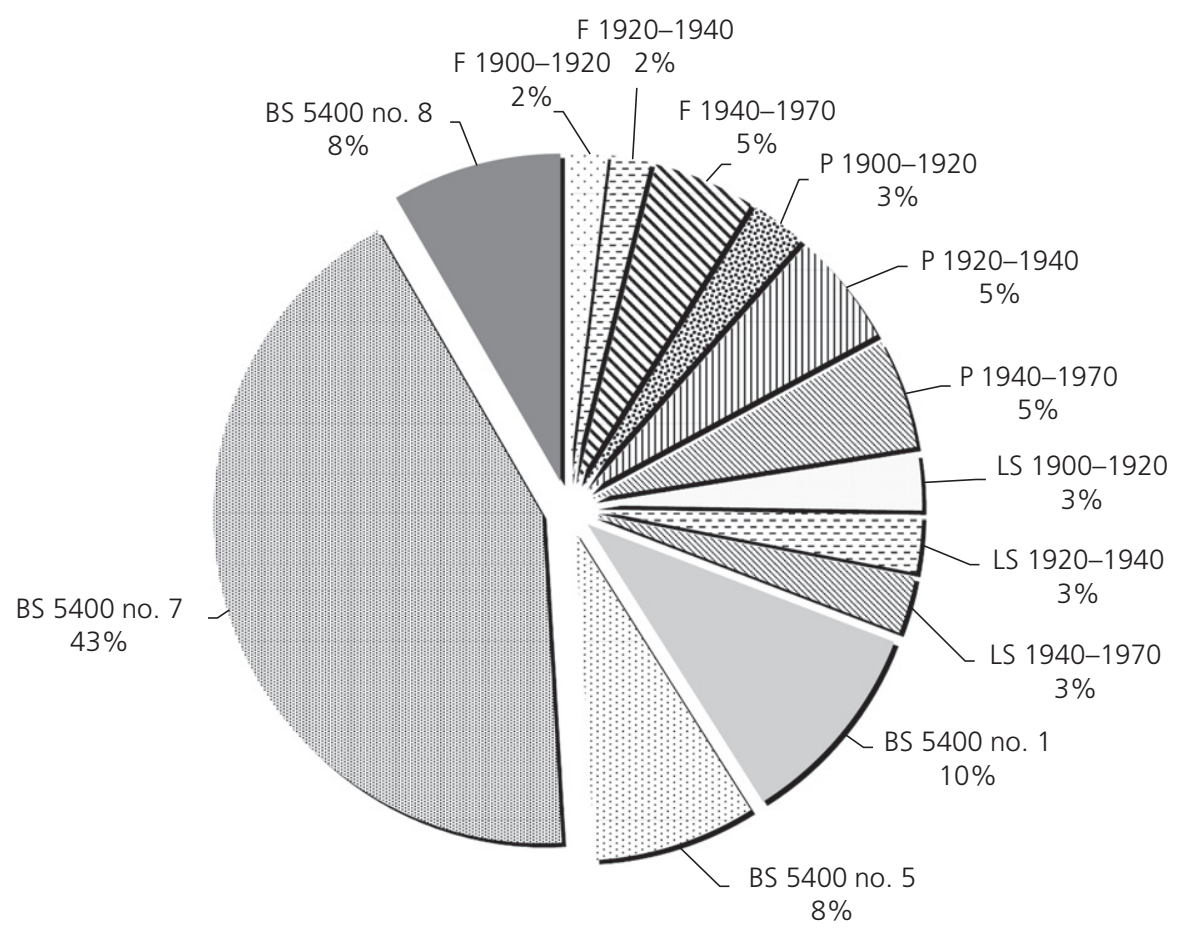

Figure 13. Standardised train set: fatigue damage for a $10 \mathrm{~m}$ bridge span $(F=$ freight, $P=$ passenger, $L S=$ local suburban) 


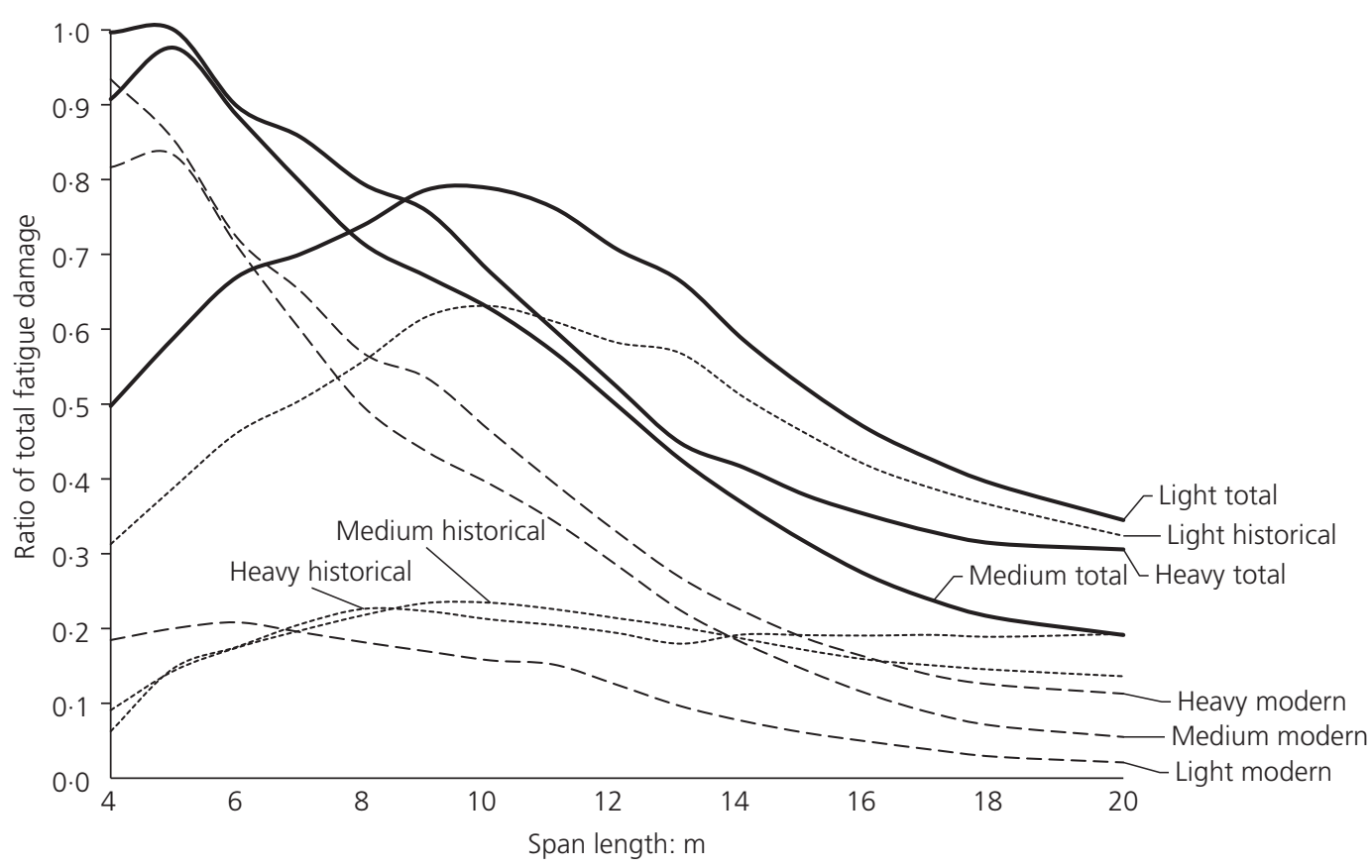

Figure 14. Comparison of fatigue damage from the light-, medium- and heavy-traffic models

stations and would only ever see passenger trains. On the other hand, a bridge located outside a busy freight terminal, away from a major city, would only be subjected to the heavy-traffic (freight train) load model.

The difference between the light- and heavy-traffic models can be seen in Figure 14, which shows the fatigue damage for all three models (medium, light and heavy traffic). The lighttraffic model consists solely of trains with large axle spacing. In comparison with the medium-traffic model, the significant increase in fatigue damage caused by historical trains with respect to the damage caused by modern trains is due to the much higher frequency of extremely damaging passenger locomotive engines. For example, for a $6 \mathrm{~m}$ span bridge, a locomotive engine causes $33 \%$ of the total damage from the historical passenger train whereas, for an $18 \mathrm{~m}$ span, the percentage contribution increases to $82 \%$ of the total damage by the passenger train.

The results from the heavy-traffic model have a high correlation with the medium-traffic model, showing that freight trains predominantly create fatigue damage with the mediumtraffic model.

It should be noted that the load models suggested in this paper are based on representative UK rail traffic. However, a comparison of the models suggested here with other historical load models, such as that suggested by UIC (1986), shows similarities in terms of the evolution of axle loads over time and train configurations. The historical traffic experienced by bridges located in different parts of a railway network is likely to be different. For example, an old railway bridge located close to a coal/iron mine is likely to have experienced heavier historical loads due to freight trains than a typical bridge located on a main passenger route. The proposed load models with the light- and heavy-traffic variations can be considered representative of the upper and lower bounds of fatigue damage originating from historical trains. Obviously, depending on the availability of detailed historical traffic data for a specific region, further detailed traffic load models can be developed.

\subsection{Wrought-iron bridges compared with mild-steel riveted bridges}

During the mid-nineteenth century the UK Board of Trade imposed design strength limits on the use of wrought iron of $77.5 \mathrm{MPa}$ in tension members and, two decades later, a limit to mild steel in tension of $100 \mathrm{MPa}$ (Fitzmaurice, 1895; Hayward, 2010, 2013). The implication from these design limits is the additional strength of mild steel, which creates a lighter design than an equivalent wrought-iron bridge (Figure 5) and therefore has a higher maximum live-load limit and increased equivalent amplitude of stress cycles due to trains travelling across the structure. This increased stress range would, under the same fatigue detail, produce significantly more fatigue damage for a steel bridge than for a wrought-iron counterpart. 


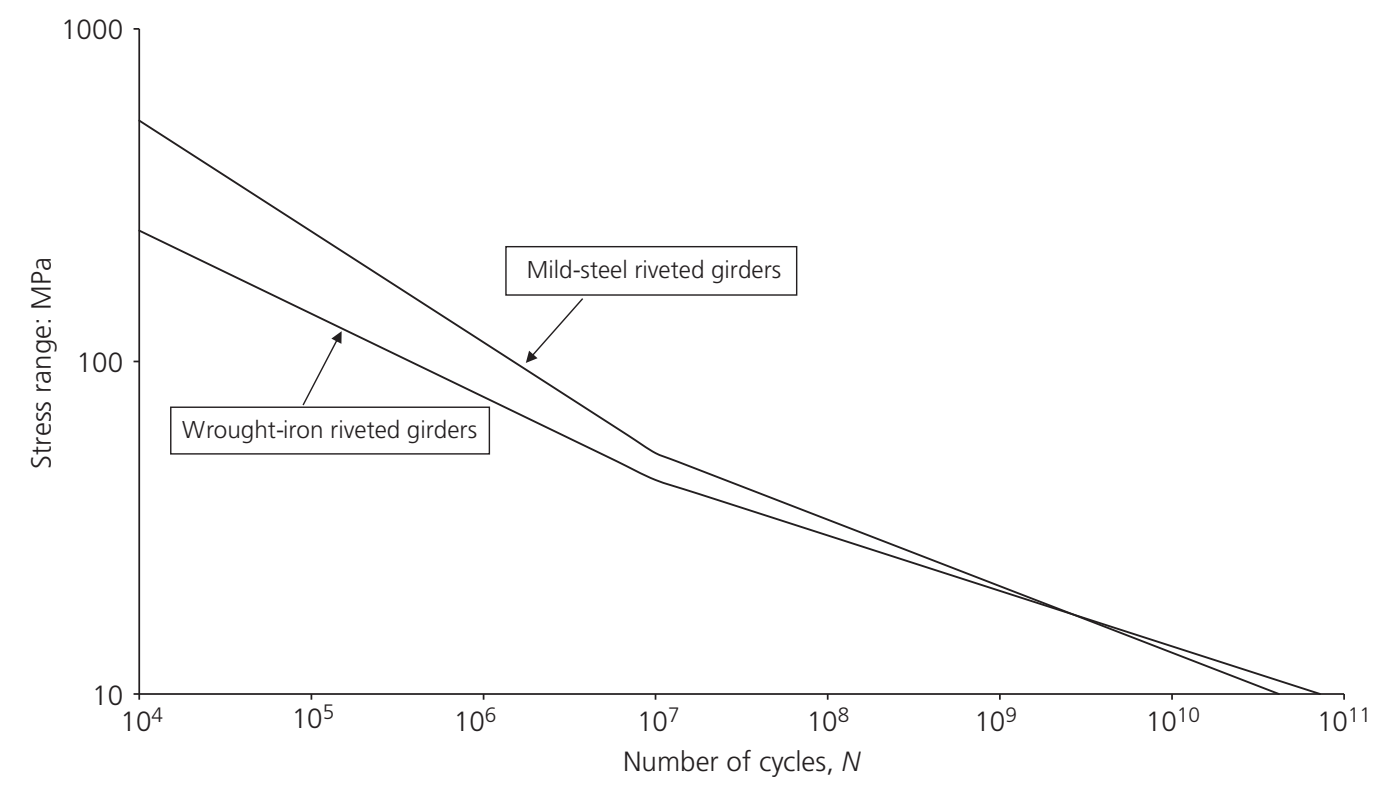

Figure 15. S-N curves for mild-steel (BS 5400 (BSI, 1980)) and wrought-iron (NR, 2006) riveted girders

However, the fatigue detail categories vary for riveted plate girders in steel compared with wrought iron. BS 5400 class D (BSI, 1980) is suggested for the former whereas a separate classification exists for wrought-iron girders (Network Rail, 2006). The $S-N$ curves of these two classes are shown in Figure 15, where it can be seen that wrought iron is more fatigue-sensitive than steel for stress ranges above $18 \mathrm{MPa}$. This additional fatigue sensitivity of wrought iron counteracts the improvement in fatigue performance due to the lower amplitude in stress cycles discussed earlier.

Another standard bridge set was created in order that both steel and wrought-iron bridges could be represented; the steel and wrought-iron bridge sets were designed to the same working stress method (Fitzmaurice, 1895; Hayward, 2010, 2013). Comparing the fatigue damage results for both material types, Figure 16 shows that the reduction in stress cycle amplitude between the steel and wrought-iron bridges is more significant than the increased fatigue sensitivity of the wrought iron. The early mild-steel riveted plate girder bridges were found to be 15$30 \%$ more fatigue-sensitive across the span range than equivalent wrought-iron riveted plate girder bridges.

\subsection{Comparison of bridges built between 1900 and 1940}

A comparison of the fatigue damage for standard bridge sets constructed between 1900 and 1940 is shown in Figure 17. For comparison purposes, the fatigue damage due solely to modern (1970) trains is also presented. The historical load models for each bridge era were created by excluding any fatigue damage from trains representing earlier periods. The figure shows that, as the standard bridge sets become younger, modern trains increasingly dominate the proportion of fatigue damage caused. For any riveted plate girder bridge constructed in wrought iron or steel up to 1940, modern train loads based on the medium-traffic model dominate the fatigue performance of short- and medium-span bridges.

\section{Conclusions}

This paper described the fatigue effects due to variations in train loading over time on riveted plate girder bridges with the aim of understanding the differing fatigue effects of historical and modern train loadings. Three historical load model variations, accounting for passenger-dominated, freight-dominated and combined railway lines, were proposed. These models were then applied to a set of typical riveted plate girder bridges to investigate fatigue trends. The parameters investigated were the type of trains passing over the bridge, the bridge span, the material of the bridge (mild steel or wrought iron) and the date of construction of the bridge.

The results showed that, for the majority of existing riveted plate girder bridges (constructed around 1900), modern trains (1970 to 2010) cause the majority of fatigue damage for bridge spans of less than $14 \mathrm{~m}$, as compared with historical trains from 1900 to 1970 . The fundamental effect of increasing axle loads over time was observed to override the other identified effects of variations in train frequency, train length and loading lifetime. The results presented in this paper can be easily used during fatigue assessments to identify and quantify 


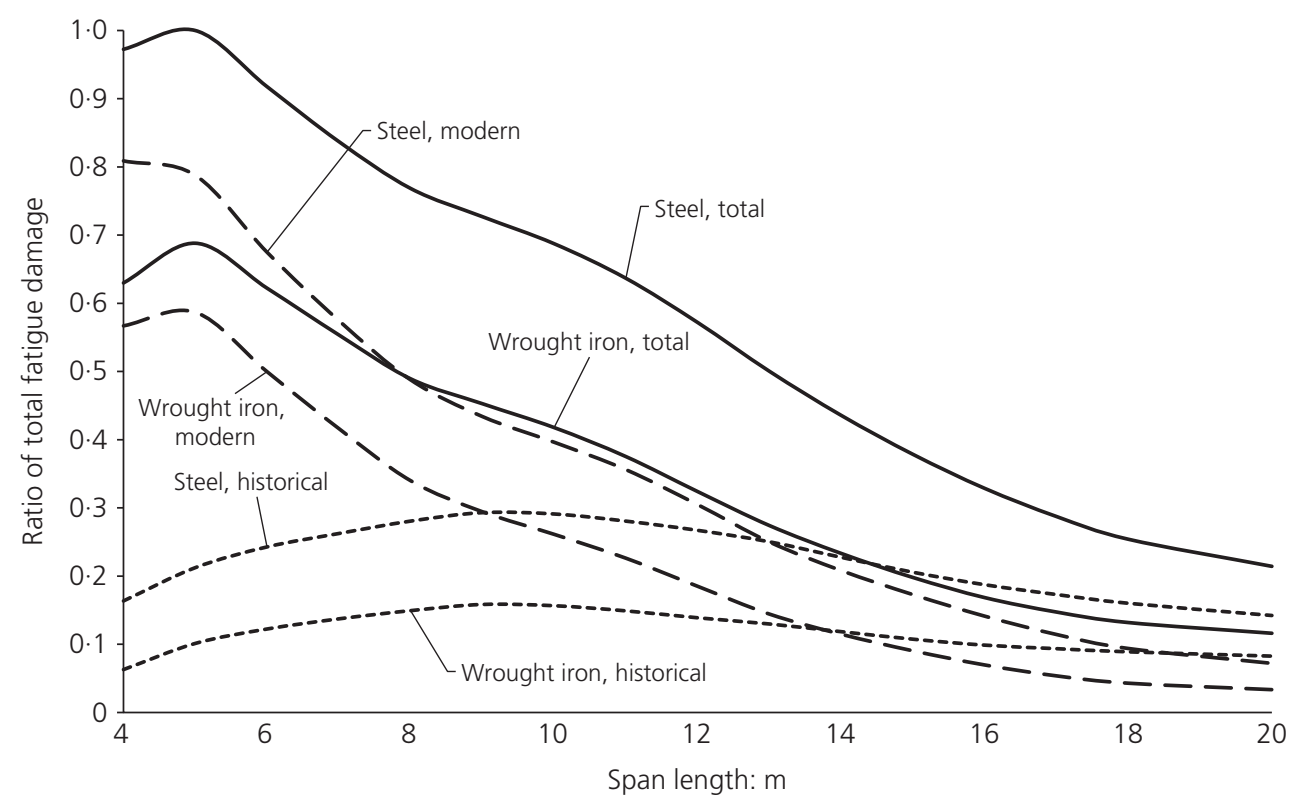

Figure 16. Comparison of fatigue damage in steel and wrought-iron bridges

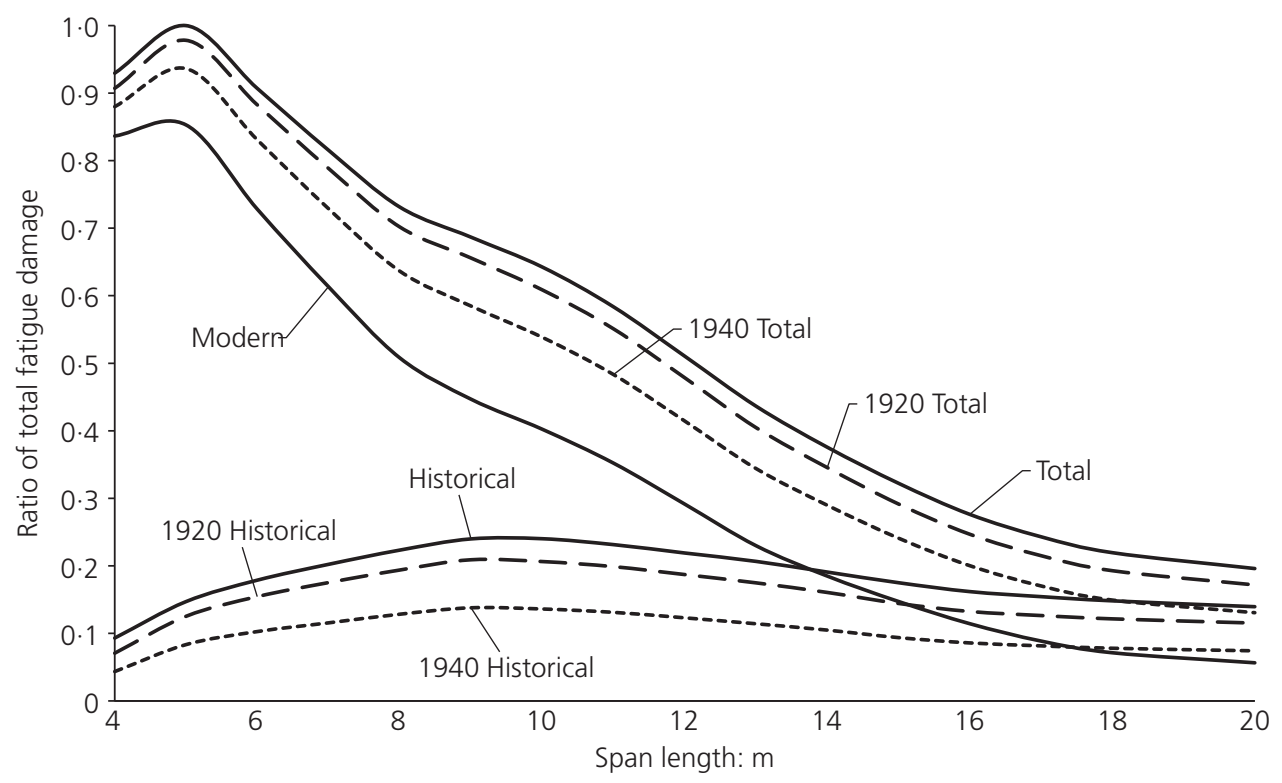

Figure 17. Comparison of bridges constructed between 1900 and 1940

the significance of historical loading on the accumulation of fatigue damage for different bridge spans. Obviously, the configuration and intensity of historical rail traffic will vary on different railway lines (routes) - some routes will be more freight-dominated and some will be more passengerdominated. Nevertheless, the results presented in this paper show that, in some cases, the effect of historical traffic may not be insignificant.

A comparison of wrought-iron and mild-steel main girders showed that, due to the increased strength of early mild steel compared with wrought iron, higher fatigue damage 
accumulates in steel girders than equivalent wrought-iron details. This increased fatigue sensitivity of steel riveted plate girders varied from $20 \%$ for short-span bridges to $10 \%$ for longer span riveted bridges. Furthermore, by investigating the influence of the year of bridge construction, it was found that the younger a riveted plate girder bridge is, the more dominant is the effect of modern trains on the overall fatigue damage caused.

The historical load models presented in this paper can be used during fatigue assessments of old metallic bridge structures and provide a more reliable prediction of the remaining life of such bridges. In practical terms, even a small extension in the fraction of the remaining life of a bridge, which is often actively sought by infrastructure managers, brought about through a more refined assessment, can lead to better allocation of maintenance funding.

\section{REFERENCES}

Akesson B (1994) Fatigue Life of Riveted Railway Bridges. PhD thesis, Chalmers University of Technology, Gothenburg, Sweden, Publ. S94:6.

Al-Emrani M (2005) Fatigue performance of stringer-to-floor-beam connections in riveted railway bridges. Journal of Bridge Engineering ASCE 10(2): 179-185.

Al-Emrani M and Kliger R (2003) FE analysis of stringer-to-floor-beam connections in riveted railway bridges. Journal of Constructional Steel Research 59(7): 803-818.

Bell B (2007) European Railway Bridge Demographics - Deliverable D2.1. Sustainable Bridges Project: Assessment for Future Traffic Demands and Longer Lives.

BSI (1980) BS 5400: Steel, concrete and composite bridges - part 10: code of practice for fatigue. BSI, London, UK.

Coucher I, Austin C, Leunig Tet al. (2008) The Billion Passenger Railway. Lessons from the Past: Prospects for the Future. ATOC, London, UK.

Fitzmaurice M (1895) Plate-Girder Railway Bridges. E \& FN Spon, London, UK.
Hayward ACG (2010) Trains loads on Bridges 1825 to 2010. International Journal for the History of the Engineering \& Technology 81(2): 159-191.

Hayward ACG (2013) Train loading on bridges since Stephenson's Rocket. Proceedings of the Institution of Civil Engineers - Bridge Engineering 167(4): 326-337, http://dx.doi.org/10.1680/ bren.11.00029.

Imam B (2006) Fatigue Analysis of Riveted Railway Bridges. $\mathrm{PhD}$ thesis, University of Surrey, Guildford, UK.

Imam BM and Righiniotis TD (2010) Fatigue evaluation of riveted railway bridges through global and local analysis. Journal of Constructional Steel Research 66(11): 1411-1421.

Imam B, Righiniotis TD, Chryssanthopoulos MK and Bell B (2006) Analytical fatigue assessment of a typical riveted UK rail bridge. Proceedings of the Institution of Civil Engineers - Bridge Engineering 159(3): 105-116, http://dx.doi.org/10.1680/ bren.2006.159.3.105.

Imam BM, Righiniotis TD and Chryssanthopoulos MK (2008) Probabilistic fatigue evaluation of riveted railway bridges. Journal of Bridge Engineering ASCE 13(3): 237-244.

Imam BM, Chryssanthopoulos MK and Frangopol DM (2012) Fatigue system reliability analysis of riveted railway bridge connections. Structure and Infrastructure Engineering 8(10): 967-984.

IMechE (2009) Rail Freight Getting on the Right Track. Institution of Mechanical Engineers, London, UK.

Leach G (2002) Evolution not Revolution - The Future of the Railways. The Institute of Directors, London, UK.

Miner MA (1945) Cumulative damage in fatigue. Journal of Applied Mechanics 12(3): A159-A164.

Network Rail (2006) NR/GN/CIVI025 Issue 3: The Structural Assessment of Underbridges. Network Rail, London, UK.

Pipinato A, Pellegrino C and Modena C (2012) Fatigue damage estimation in existing railway steel bridges by detailed loading history analysis. ISRN Civil Engineering 2012: 231674.

Righiniotis TD, Imam BM and Chryssanthopoulos MK (2008) Fatigue analysis of riveted railway bridge connections using the theory of critical distances. Engineering Structures 30(10): 2707-2715.

UIC (International Union of Railways) (1986) UIC Code 779-1 $\mathrm{R}$ : Recommendations for determining the load carrying capacity of existing metal structures. UIC, Paris, France.

Whiteing A (2003) Multimodal Freight Transport in Great Britain. University of Huddersfield, Huddersfield, UK and The Institute of Logistics and Transport, Corby, UK.

\section{How can you contribute?}

To discuss this paper, please email up to 500 words to the editor at journals@ice.org.uk. Your contribution will be forwarded to the author(s) for a reply and, if considered appropriate by the editorial board, it will be published as discussion in a future issue of the journal.

Proceedings journals rely entirely on contributions from the civil engineering profession (and allied disciplines). Information about how to submit your paper online is available at www.icevirtuallibrary.com/page/authors, where you will also find detailed author guidelines. 